\title{
The Perverse Response of Interest Rates
}

\author{
Virginie Boinet \\ and \\ Christopher Martin \\ Brunel Business School \\ Brunel University \\ Uxbridge \\ Middlesex UB8 3PH
}

June 2006

\begin{abstract}
We argue that an increase in aggregate demand can lead to a reduction in the interest rate. This apparently perverse optimal response of interest rates can occur when the Phillips curve is non-linear. In that case, an increase in aggregate demand tends to increase inflation and output but also to change the weight on inflation in the optimal monetary policy rule. Although the first two effects tend to increase interest rates, the latter effect can imply lower interest rates. If this effect dominates, interest rates can fall.
\end{abstract}




\section{1) Introduction}

This paper argues that the optimal behaviour of interest rates can be surprising. We analyse the optimal response of interest rates to an anticipated increase in aggregate demand. In these circumstances we would expect to observe an increase in interest rates. However we demonstrate that interest rates can in fact decrease.

This apparently perverse response of interest rates can occur when the Phillips curve or aggregate supply curve is non-linear. The optimal response of interest rates to inflation depends on the slope of the Phillips curve. If the Phillips curve is linear, the slope is constant and the familiar constant proportional response of interest rates to inflation that is characteristic of the Taylor rule (Taylor, 1993) is obtained. However, if the Phillips curve is non-linear, the slope of the Phillips curve is not constant and so the optimal response of interest rates to inflation is a function of the output gap. This interaction is the source of the perverse response. An increase in aggregate demand tends to increase inflation and output; both these effects tend to increase the interest rate. However if the Phillips curve is non-linear, the increase in output also changes the weight on inflation in the optimal monetary policy rule and hence changes the relative importance of inflation and output in interest rate determination. If interest rates were high because inflation was above target, a reduction in the weight on inflation can lead to lower interest rates. Similarly, if interest rates were low because inflation was below target, an increase in the weight on inflation can lead to lower interest rates even though both inflation and output have increased.

The remainder of the paper is structured as follow. We outline our model in section 2), derive our optimal monetary policy rule in section 3) and derive sufficient conditions for the perverse response to occur in section 4). In section 5) we consider some examples and establish that perversity can occur for values of inflation and output that are observed in the data, suggesting that this effect may be more than a theoretical curiosity. Section 6) concludes. 


\section{2) The Model}

The economy comprises a conventional aggregate demand curve and a less conventional nonlinear aggregate supply curve. The aggregate demand curve is

$$
y_{t}=-\rho_{i}\left(i_{t}-E_{t} \pi_{t+1}\right)+E_{t} y_{t+1}+\rho_{\bar{y}} \bar{y}_{t}+\varepsilon_{t}^{d}
$$

where $\mathrm{y}$ is the output gap, $\mathrm{i}$ is the nominal interest rate, $\pi$ is the inflation rate, $\bar{y}$ is an exogenous component to aggregate demand, $\varepsilon_{t}^{d}$ is an i.i.d demand shock and $\rho_{i}$ and $\rho_{\bar{y}}$ are positive coefficients. The Phillips curve or aggregate supply curve is

$$
\pi_{t}=\gamma\left(y_{t}\right)+\theta E_{t} \pi_{t+1 t}+\varepsilon_{t}^{s}
$$

where $\varepsilon_{t}^{s}$ is an i.i.d supply shock and $\theta$ is a positive coefficient. The short-run trade-off between inflation and output is captured by the function $\gamma($.$) . We assume that the Phillips$ curve passes through the origin, so $\gamma(0)=0$, and does not slope down, so $g\left(y_{t}\right) \geq 0$, where $g\left(y_{t}\right)=\frac{d \pi_{t}}{d y_{t}}$ is the slope of the Phillips curve. This latter assumption ensures that an increase in output never results in a reduction in inflation along the Phillips curve. At this stage we do not otherwise restrict the shape of the Phillips curve.

We assume that policymakers choose the nominal interest rate at the beginning of period $t$ on the basis of information available at the end of period ( $\mathrm{t}-1)$. Their optimisation problem is 


$$
\operatorname{Min}_{\left\{i_{t}\right\}} E_{t-1} \sum_{j=0}^{\infty} \delta^{j} L_{t+j}
$$

subject to (1) and (2), where $\delta$ is the discount factor and

(4) $\quad L_{t}=\frac{1}{2}\left(\pi_{t}-\pi^{*}\right)^{2}+\frac{\lambda}{2} y_{t}^{2}+\frac{\mu}{2}\left(i_{t}-i^{*}\right)^{2}$

is a conventional per-period quadratic loss function where $\pi^{*}$ is the inflation target or desired inflation rate, $i^{*}$ is the equilibrium or desired nominal interest rate and $\lambda$ and $\mu$ are positive coefficients that capture the relative weights on output and interest rates in the loss function.

\section{3) Optimal Monetary Policy}

Following the existing literature (eg Clarida et al, 1999) by solving this optimisation problem under discretion, the optimal monetary policy rule can be expressed as

$$
i_{t}=i^{*}+\frac{\rho \lambda}{\mu} E_{t-1} y_{t}+\frac{\rho g\left(y_{t}\right)}{\mu} E_{t-1}\left(\pi_{t}-\pi^{*}\right)
$$

The response of interest rates to inflation in (5) depends on $g\left(y_{t}\right)$, the slope of the Phillips curve, and is thus a function of the output gap. This policy rule is a generalisation of the familiar Taylor rule, which is obtained if the Phillips curve is linear, in which case $g\left(y_{t}\right)$ is constant. 


\section{4) The perverse response of Interest Rates}

Suppose now that there is an expected increase in aggregate demand, so $E_{t-1} \bar{y}_{t}$ increases. The response of interest rates is

$$
\frac{d i_{t}}{d E_{t-1} \bar{y}}=\rho_{\bar{y}} \frac{d i_{t}}{d E_{t-1} y_{t}}=\rho_{\bar{y}}\left[\frac{\rho \lambda}{\mu}+\frac{\rho}{\mu} E_{t-1} g\left(y_{t}\right) \frac{d \pi_{t}}{d y_{t}}+\frac{\rho}{\mu} E_{t-1} g^{\prime}\left(y_{t}\right)\left(\pi_{t}-\pi^{*}\right)\right]
$$

where $g^{\prime}\left(y_{t}\right)=\frac{d^{2} \pi_{t}}{\left(d y_{t}\right)^{2}}$ is the derivative of $g\left(y_{t}\right)$.

The first term in (6) reflects the second term in (5), where an increase in output always increases interest rates. The final two terms in (6) reflect the final term in (5). The second term in (6) states that an increase in inflation will always increase interest rates, for a given slope of the Phillips curve and hence a given weight on inflation in the optimal policy rule. The third term in (6) captures the effect of the change in the slope of the Phillips curve induced by the change in aggregate demand. This term can be positive or negative depending whether the slope of the Phillips curve increases or decreases and whether inflation is above or below the target. The perverse response of interest rates occurs if (6) is negative.

Since $\frac{d \pi_{t}}{d y_{t}}=g\left(y_{t}\right)$, this occurs if

$$
\lambda+E_{t-1} g\left(y_{t}\right)^{2}<-E_{t-1} g^{\prime}\left(y_{t}\right)\left(\pi_{t}-\pi^{*}\right)
$$

The increase in aggregate demand can lead to a reduction in interest rates in two situations. First, if the increase in aggregate demand moves the economy onto a steeper 
portion of the Phillips curve then the weight on inflation increases. If inflation is below the target or desired level, then $g^{\prime}\left(y_{t}\right)\left(\pi_{t}-\pi^{*}\right)<0$ and a perverse response is possible. Second, if the increase in aggregate demand moves the economy onto a flatter portion of the Phillips curve, then the weight on inflation decreases. If inflation is above target, then $g^{\prime}\left(y_{t}\right)\left(\pi_{t}-\pi^{*}\right)<0$ and a perverse response is again possible.

Perverse responses to a reduction in aggregate demand are also possible. These occur either when a reduction in aggregate demand moves the economy onto a flatter portion of the Phillips curve (so $g^{\prime}\left(y_{t}\right)>0$ ) and inflation is below target or when a reduction in aggregate demand moves the economy onto a steeper portion of the Phillips curve (so $g^{\prime}\left(y_{t}\right)<0$ ) and

inflation is above target. In either case, $g^{\prime}\left(y_{t}\right)\left(\pi_{t}-\pi^{*}\right)<0$ and the inequality in (7) may be satisfied.

Perverse responses cannot occur if the Phillips curve is linear, since $g^{\prime}\left(y_{t}\right)=0$, or if inflation is on target, so $\left(\pi_{t}-\pi^{*}\right)=0$. The perverse response is more likely when $\lambda$ is larger and when, ceteris paribus, the inflation gap $\left(\pi_{t}-\pi^{*}\right)$ is larger. The effect of the output gap is more difficult to assess since it affects both sides of the inequality in (7). We investigate this further in the next section using specific forms for the Phillips curve.

\section{5) An illustration}

In this section, we investigate under which circumstances the perverse response is more likely to occur, considering three alternative forms for the Phillips curve. We establish that the perverse response can occur for values of inflation and output that are observed in the data.

We first consider the case where the Phillips curve is given by 


$$
\gamma\left(y_{t}\right)=\alpha \frac{e^{\gamma y_{t}}-1}{\gamma}
$$

This relationship is convex if $\gamma>0$. Convexity of the Phillips curve, first proposed by Turner (1995) and Laxton et al (1995), has been frequently assumed in recent models. Figure 1a) depicts the convex Phillips curve. Since the Phillips curve becomes monotonically steeper as output increases $\left(g^{\prime}\left(y_{t}\right)>0\right)$, the perverse response can only occur if inflation is below target. Figure $1 b$ ) depicts both sides of the inequality in (7) in the case where $\alpha=1, \gamma=0.9, \lambda=0.5$ and $\left(\pi_{t}-\pi^{*}\right)=-2 \%$ (full details of these and other simulations are available from the authors upon request). The RHS of (7), $-E_{t-1} g^{\prime}\left(y_{t}\right)\left(\pi_{t}-\pi^{*}\right)$, is represented by the dotted line. This exceeds the LHS of (7), $\lambda+E_{t-1} g\left(y_{t}\right)^{2}$, represented by the solid line, when the output gap is between approximately $-1.2 \%$ and $0.4 \%$, indicating that a perverse response occurs when the output gap is in this range. Other simulations using different values of the inflation gap $\left(\pi_{t}-\pi^{*}\right)$ confirm that perverse responses frequently occur for values of inflation and output that have been observed in the data.

We also consider the case where the Phillips curve is concave, as has been suggested by Stiglitz (1997) and Eisner (1997). The Phillips curve in (8) is concave if $\gamma<0$. This Phillips curve is depicted in figure 2a). Since the slope of the Phillips curve is decreasing in output, perversity can only occur if inflation is above target. Figure 2b) depicts both sides of the inequality in (7) using the same parameter values as in figure 1), except that $\left(\pi_{t}-\pi^{*}\right)=2 \%$. We observe that the RHS of (8) exceeds the LHS when the output gap approximately between $-0.4 \%$ and $1.2 \%$, so perversity occurs when the output gap is in this range.

Finally, we consider the Phillips curve 


$$
\gamma\left(y_{t}\right)=\alpha y_{t} \frac{e^{\gamma y_{t}{ }^{2}}-1}{\gamma}
$$

This Phillips curve is concave when the output gap is negative and convex when the output gap is positive. The type of Phillips curve has been suggested by Filardo (1998). Figure 3a) depicts the Phillips curve in this case. If inflation is above target, perversity can only occur when $g^{\prime}\left(y_{t}\right)<0$ which occurs when the output gap is negative. Similarly, if inflation is below target, perversity can only occur if the output gap is positive. Figure $3 b$ ) depicts both sides of the inequality in (7) for the case when $\alpha=1, \gamma=0.1, \lambda=0.5$ and $\left(\pi_{t}-\pi^{*}\right)=-1 \%$. The RHS of (7) exceeds the LHS when the output gap is between approximately $0.1 \%$ and $0.85 \%$, so a perverse response occurs when the output gap is in this region. For the same parameter values, perversity occurs when the output gap is between $-0.1 \%$ and $-0.85 \%$, if $\left(\pi_{t}-\pi^{*}\right)=1$.

\section{6) Conclusions}

This paper has argued that an increase in aggregate demand can lead to a reduction in interest rates. This apparently perverse response of interest rates can occur when the Phillips curve is non-linear. In that case, an increase in aggregate demand tends to increase inflation and output but also to change the weight on inflation in the optimal monetary policy rule. Although the first two effects tend to increase interest rates, the latter effect can imply lower interest rates. If the latter effect dominates, interest rates can fall. We have argued that the perverse response can occur for values of inflation and output that are observed in the data. In future work, we intend to search for instances when the perverse response occurred. 


\section{References}

Clarida, R, J Gali, and M Gertler. 1999. "The Science of Monetary Policy: A New Keynesian Perspective.” Journal of Economic Literature, 37 (December), pp. 1661-1707.

Eisner, R. 1997. "Improving the global economy: Keynesian and the growth in output and employment," in P. Davidson and J. Kregel, eds., New view of the NAIRU. Edward Elgar.

Filardo, A. 1998. "New evidence on the output cost of fighting inflation." Federal Reserve Bank of Kansas City Economic Review, 83, pp. 33-61.

Laxton, D., Meredith, G. and Rose, D. 1995. “Asymmetric Effects of Economic Activity on Inflation: Evidence and Policy Implications.” IMF Staff Papers, 42 (2).

Stiglitz, J. 1997. "Reflections on the Natural Rate Hypothesis." Journal of Economic Perspectives, 11, pp. 3-10.

Taylor, J. 1993. "Discretion versus policy rules in practice." Carnegie-Rochester Conference Series on Public Policy, 39, pp 195-214.

Turner, D. 1995. "Speed Limit and Asymmetric Effects from the Output Gap in the Seven Major Countries.” OECD Economic Studies, 24, pp. 57-88 
Figure 1.a

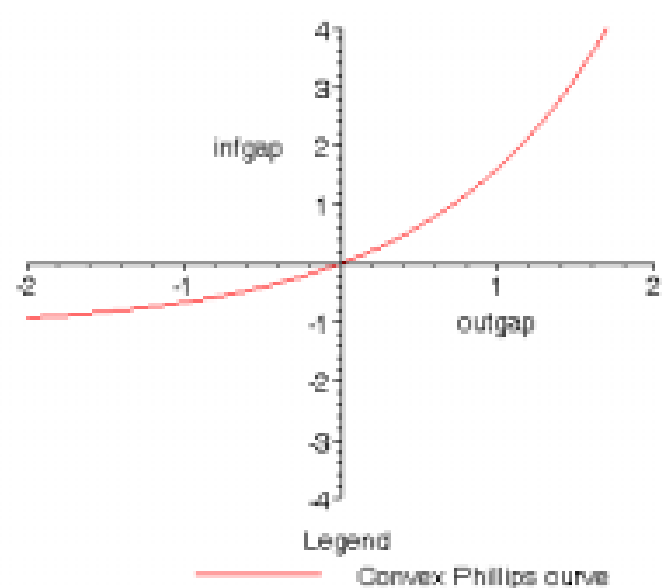

Figure 2.a

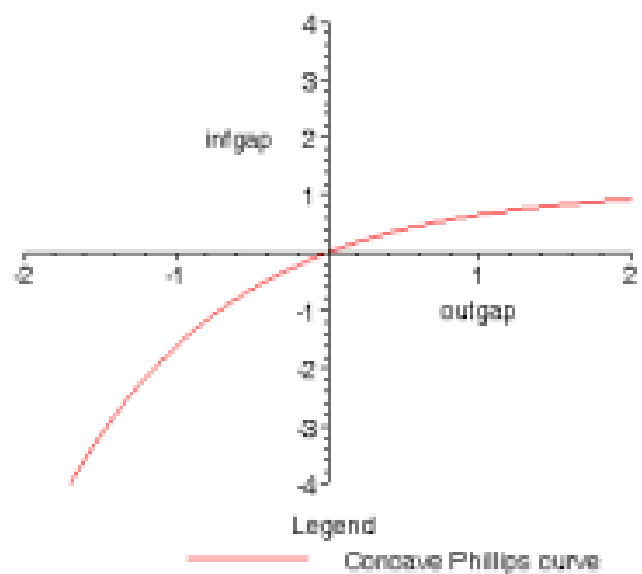

Figure 3.a

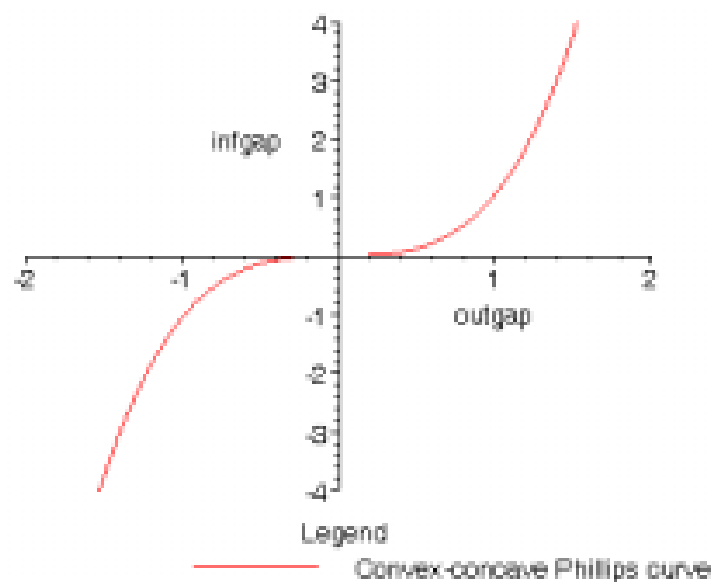

Figure 1.b

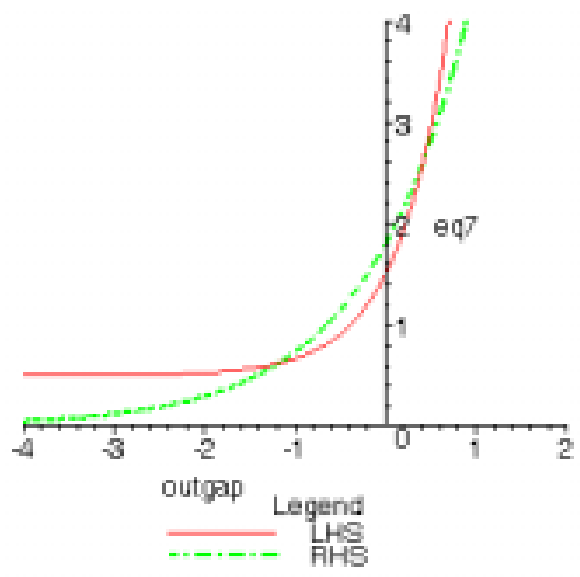

Figure 2.b

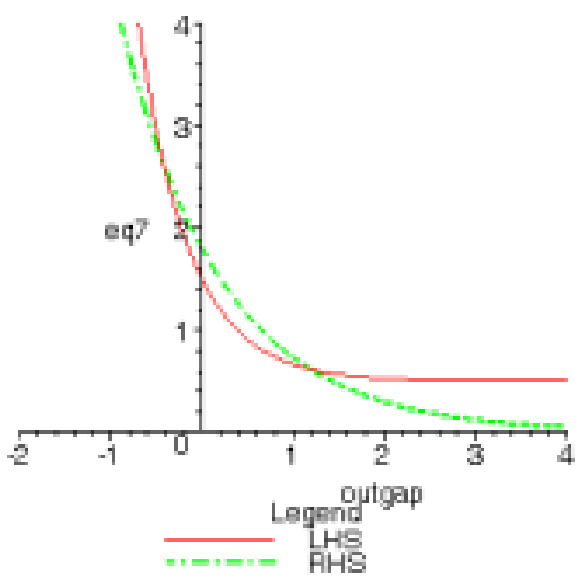

Figure 3.b

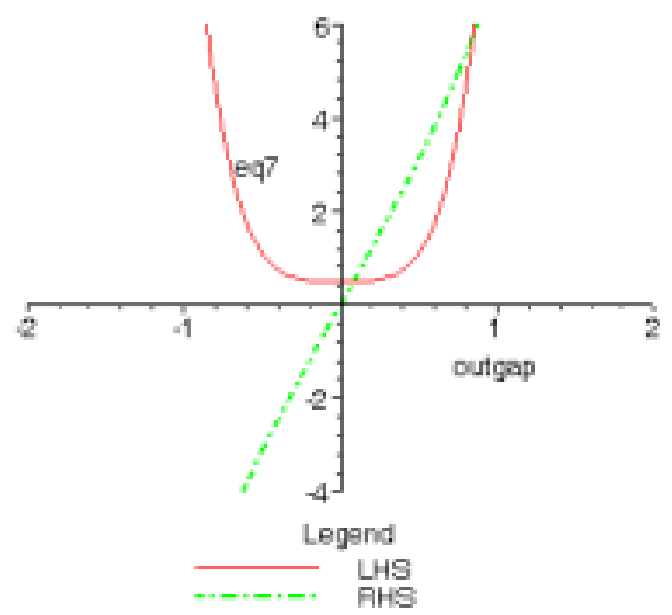

